\title{
Partially responsive celiac disease resulting from small intestinal bacterial overgrowth and lactose intolerance Uday C Ghoshal ${ }^{* 1}$, Ujjala Ghoshal ${ }^{2}$, Asha Misra ${ }^{1}$ and Gourdas Choudhuri ${ }^{1}$
}

Address: ${ }^{1}$ Department of Gastroenterology, Sanjay Gandhi Postgraduate Institute of Medical Sciences, Lucknow 226014, India and ${ }^{2}$ Department of Microbiology, Sanjay Gandhi Postgraduate Institute of Medical Sciences, Lucknow 226014, India

Email: Uday C Ghoshal* - ghoshal@sgpgi.ac.in; Ujjala Ghoshal - ujjala@sgpgi.ac.in; Asha Misra - ghoshal@sgpgi.ac.in; Gourdas Choudhuri - gc@sgpgi.ac.in

* Corresponding author

Published: 22 May 2004

BMC Gastroenterology 2004, 4:10
Received: 24 December 2003

Accepted: 22 May 2004

This article is available from: http://www.biomedcentral.com/I47I-230X/4/10

(C) 2004 Ghoshal et al; licensee BioMed Central Ltd. This is an Open Access article: verbatim copying and redistribution of this article are permitted in all media for any purpose, provided this notice is preserved along with the article's original URL.

\begin{abstract}
Background: Celiac disease is a common cause of chronic diarrhea and malabsorption syndrome all over the world. Though it was considered uncommon in India in past, it is being described frequently recently. Some patients with celiac disease do not improve despite gluten free diet (GFD). A study described 15 cases of celiac disease unresponsive to GFD in whom small intestinal bacterial overgrowth (SIBO) or lactose intolerance was the cause for unresponsiveness.

Case presentation: During a three-year period, 12 adult patients with celiac disease were seen in the Luminal Gastroenterology Clinic in a tertiary referral center in northern India. Two of these 12 patients (16.6\%), who did not fully respond to GFD initially, are presented here. Unresponsiveness resulted from SIBO in one and lactose intolerance in the other. The former patient responded to antibiotics and the latter to lactose withdrawal in addition to standard GFD.

Conclusion: In patients with celiac disease partially responsive or unresponsive to GFD, SIBO and lactose intolerance should be suspected; appropriate investigations and treatment for these may result in complete recovery.
\end{abstract}

\section{Background}

Celiac disease is a common cause of chronic diarrhea and malabsorption syndrome (MAS) all over the world. Though it was considered uncommon in India in past, it is being described frequently recently $[1,2]$. Some patients with celiac disease do not improve despite gluten free diet (GFD). Tursi et al described 15 cases of celiac disease unresponsive to GFD in whom small intestinal bacterial overgrowth (SIBO) or lactose intolerance was the cause of unresponsiveness [3]. We describe two adult patients with celiac disease only partially responsive to GFD; unresponsiveness resulted from SIBO in one and lactose intolerance in the other.

\section{Case presentation}

During a 3-y period from July 2000 to July 2003, 12 adult patients with celiac disease diagnosed using standard criteria [2] were seen in the Luminal Gastroenterology Clinic of the Department of Gastroenterology in a tertiary referral center in northern India. All except two (16.6\%) of them responded clinically to GFD. The data of the two patients, who were initially unresponsive to standard GFD is presented below.

\section{Case I}

A 35-y-old female presented with chronic large volume diarrhea for more than 3-y. She passed 20 liquid (including nocturnal), frothy, pale, greasy, unusually offensive 


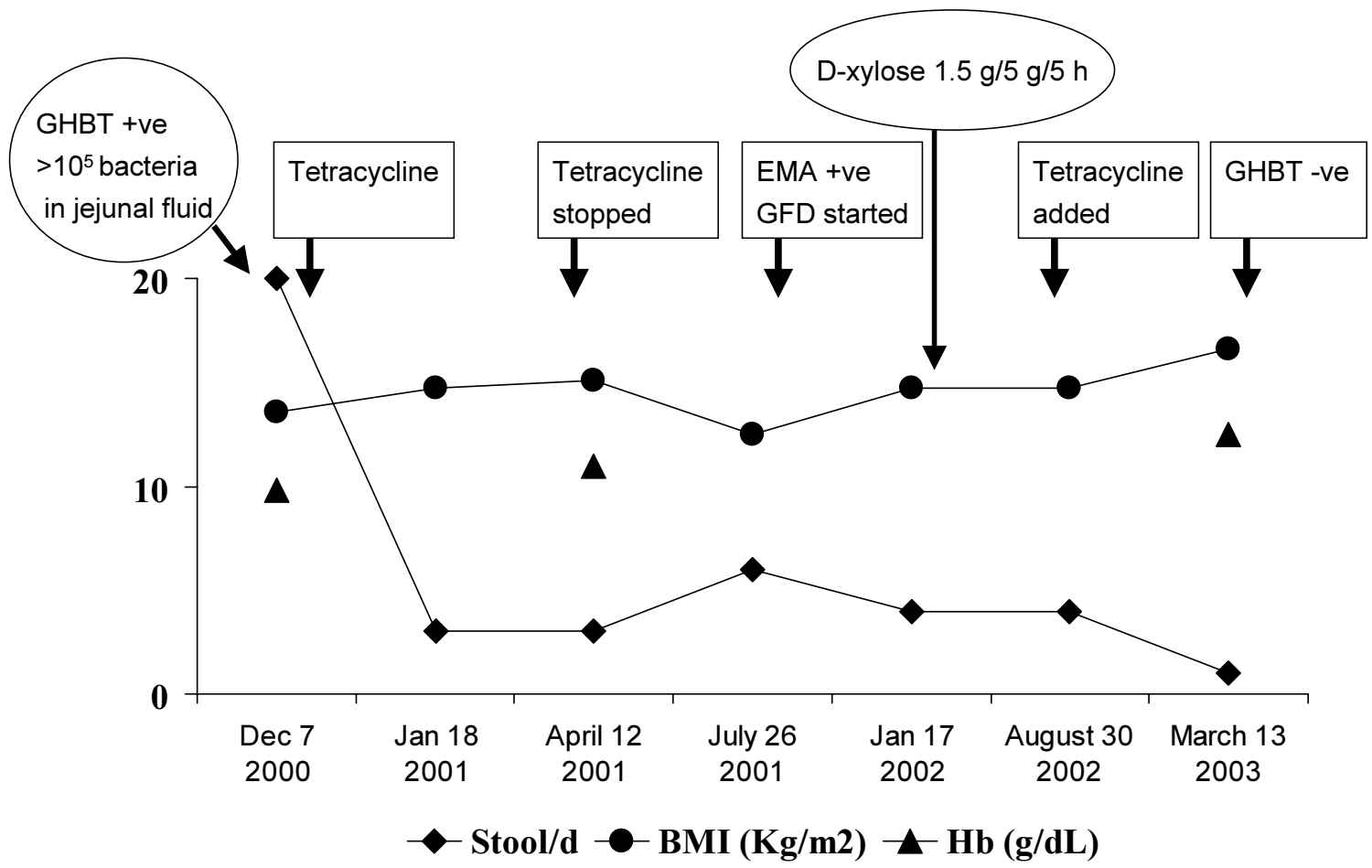

Figure I

Course of a patient with celiac disease. Her response to gluten free diet (GFD) was inadequate despite a good compliance. This might have resulted from small intestinal bacterial overgrowth (SIBO) as addition of antibiotics with disappearance of SIBO (as evidenced by a negative glucose hydrogen breath test, GHBT) resulted in resolution of symptoms. EMA: anti-endomysial antibody.

stools. She never passed blood with these stools. She lost $11 \mathrm{~kg}$ weight in $3 \mathrm{y}$. She had temporary reduction in diarrhea and gain in weight while on anti-tubercular drug therapy given 3 mo after onset of this disease. She was emaciated (body mass index $13.7 \mathrm{~kg} / \mathrm{m}^{2}$ ), pale, had angular stomatitis and clubbed fingers. Investigations revealed: Hb 98 g/L (normal 120-150), total leukocyte count $5.9 \times$ $10^{9} / \mathrm{L}\left(\right.$ normal $\left.4.0-11.0 \times 10^{9}\right)$ with normal differential counts, serum albumin $30 \mathrm{~g} / \mathrm{L}$ (normal 40-60), serum iron $9.7 \mu \mathrm{mol} / \mathrm{L}$ (normal 11-29); serum bilirubin and transaminases were within normal limits. ELISA test for human immunodeficiency virus was negative. Sudan III stained spot-stool specimen showed 15 fat droplets/high power field (normal $\leq 10$ ); urinary excretion over $5 \mathrm{~h}$ after ingestion of $5 \mathrm{~g}$ D-xylose was $0.29 \mathrm{~g}$ (normal $\geq 1 \mathrm{~g}$ ). Esophagogastroduodenoscopy revealed flattened duodenal folds and biopsy revealed subtotal villous atrophy, crypt hyperplasia and increased intra-epithelial lymphocytes (Marsh's stage IIIB) [4]. Jejunal aspirate culture by a method described by us previously $[5,6]$ revealed growth of Klebsiella pneumoniae and Pseudomonas aeruginosa (colony counts $>10^{5} \mathrm{CFU} / \mathrm{ml}$ ). Glucose hydrogen breath test (GHBT) by a standard method [5] revealed fasting value of 36 ppm and highest value of 200 ppm 60 minutes after $100 \mathrm{~g}$ glucose. This was interpreted as a positive test for SIBO as per standard criteria [5]. Lactulose hydrogen 
breath test by a standard technique [5] revealed two peaks; the first peak was at $110 \mathrm{~min}$ after $15 \mathrm{ml}$ lactulose (24 ppm above basal, basal value $17 \mathrm{ppm}$ ); this could be related to SIBO. The time to second peak was $200 \mathrm{~min}$ (which corresponds to oro-cecal transit time, OCTT) after lactulose ingestion (21 ppm above basal). Therefore, OCTT was prolonged (median value in healthy subjects in India 65 min, range 40-110) [5]. The subsequent treatment and course is depicted in Fig. 1. Though she responded to treatment with tetracycline $500 \mathrm{mg}$ t.i.d over 2 months, diarrhea recurred with reduction in body weight 3 months after stopping the drug. At this time, result of anti-endomysial antibody test using indirect immunofluorescence assay (Binding Site, UK) was available and was positive. She was started on GFD. Despite good compliance to it, there was inadequate symptomatic response (Fig. 1), even though D-xylose test result was normal one y after presentation [urinary excretion over 5 $\mathrm{h}$ after ingestion of $5 \mathrm{~g}$ D-xylose $1.5 \mathrm{~g}$ (normal $\geq 1 \mathrm{~g}$ )]. In view of finding SIBO at presentation and transient response to antibiotics, tetracycline was re-started. She improved symptomatically with gain in weight and normalization of hemoglobin. GHBT repeated at this stage failed to show persistence of SIBO.

\section{Case 2}

A 44-y-old female presented with large volume diarrhea for $14 \mathrm{y}$. She passed 6-7 large volume, watery, explosive stools everyday (including nocturnal). She gave history of reduction of diarrhea on fasting and increase on taking milk. She lost $9 \mathrm{~kg}$ weight in last $1 \mathrm{y}$. Antibiotic therapy resulted in some reduction in stool frequency. Physical examination revealed pallor and emaciation (BMI $16 \mathrm{~kg} /$ $\mathrm{m}^{2}$ ). There was no clubbing, lymphadenopathy or organomegaly. Investigations revealed: $\mathrm{Hb} 97 \mathrm{~g} / \mathrm{L}$ (normal 120-150), total leukocyte $7.7 \times 10^{3} / \mathrm{L}$ (normal $4.0-11.0$ $\times 10^{9}$ ) with normal differential counts, serum bilirubin $10.3 \mu \mathrm{mol} / \mathrm{L}$ (normal 2-18), alanine aminotransferase and alkaline phosphatase $29 \mathrm{U} / \mathrm{L}$ (normal 0-40) and 88 $\mathrm{U} / \mathrm{L}$ (normal $<150$ ), respectively. Serum total protein and albumin were 57 and 27 (normal 60-84 and 35-55) g/L, respectively; creatinine and fasting blood glucose were 53 $\mu \mathrm{mol} / \mathrm{L}$ (normal 50-110) and $3.8 \mathrm{mmol} / \mathrm{L}$ (normal 3.96.1). ELISA test for human immunodeficiency virus was negative. Stool microscopic examination did not show ova, cyst or parasite; fat in spot stool specimen stained with Sudan III stain was 16 droplets/HPF (normal $\leq 10$ droplets/HPF); urinary excretion over $5 \mathrm{~h}$ after ingestion of $5 \mathrm{~g}$ D-xylose was $0.18 \mathrm{~g}$ (normal $\geq 1 \mathrm{~g}$ ). Serum immunoglobulins were within normal limits. Esophagogastroduodenoscopy was normal and duodenal biopsy revealed mild villous atrophy and broadening, crypt villous ratio 1:2 (normal 1: 3 to 5), lymphomononuclear infiltrate in lamina propria and increased intra-epithelial lymphocytes (Marsh's stage IIIA) [4]. Antiendomysial antibody using indirect immunofluorescence assay (Binding Site, UK) was positive. Gluten free diet was started. The subsequent course is shown in Fig. 2. Though she responded to GFD to which she was fully compliant, loose stool continued with a frequency of 4 to 5/d even 8 months after GFD. Anti-endomysial antibody repeated at this stage was found negative. D-xylose test repeated at this stage showed normal result [urinary excretion over 5 $\mathrm{h}$ after ingestion of $5 \mathrm{~g}$ D-xylose $1.1 \mathrm{~g}$ (normal $\geq 1 \mathrm{~g}$ )]. A duodenal biopsy repeated 18 mo after GFD revealed maintained villous architecture, mild lymphomononuclear infiltrate in lamina propria and mildly increased intra-epithelial lymphocytes (Marsh's stage I). In view of nearly normal villous morphology and function as was evidenced by normal D-xylose test and negative antiendomysial antibody an osmotic cause like lactose intolerance was suspected. Lactose tolerance test and lactose hydrogen breath test were done with $50 \mathrm{~g}$ oral lactose. Fasting blood glucose and breath hydrogen were 4.6 $\mathrm{mmol} / \mathrm{L}$ and $10 \mathrm{ppm}$, respectively; $1 \mathrm{~h}$ post lactose values were $5.2 \mathrm{mmol} / \mathrm{L}$ and $36 \mathrm{ppm}$ respectively. She had symptoms in the form of loose stools during 3-h observation period. Based on these, a diagnosis of lactose intolerance was made and lactose-free diet was started; diarrhea resolved during follow-up (Fig. 2).

\section{Discussion and conclusion}

Diagnosis of celiac disease in both the patients was established on standard criteria [2]. We have earlier shown that half of patients with MAS resulting from various causes including celiac disease may have SIBO [6]. In patients with tropical sprue it resulted from small intestinal stasis as evidenced by prolonged OCTT [5]. Similar mechanisms may operate in patients with MAS due to other causes; the patient with celiac disease with SIBO in this report had prolonged OCTT. Prolonged OCTT has been reported by other workers in patients with celiac disease, which normalized after GFD [7]. Unabsorbed foods within the intestinal lumen may also promote growth of bacteria in small intestinal lumen. We believe that SIBO in patients with MAS due to another cause may have following clinical significances, (1) a response to antibiotics may lead to a fallacious diagnosis of tropical sprue as response to antibiotics has been considered to be an important criterion for diagnosis of this disease [8]; (2) it may be a cause for inadequate response or refractory state despite GFD as occurred in our first patient and as has been reported by Tursi et al [3]. Lactose intolerance could be another cause for such inadequate response to GFD. Lactase deficiency causing intolerance to lactose is known to be either primary or secondary; though in our patient, whether it was primary or secondary is a matter of conjecture, the latter is more likely as degenerated intestinal epithelial cells in patients with celiac disease are often found to have sparse endoplasmic reticulum, reflecting low level of digestive 


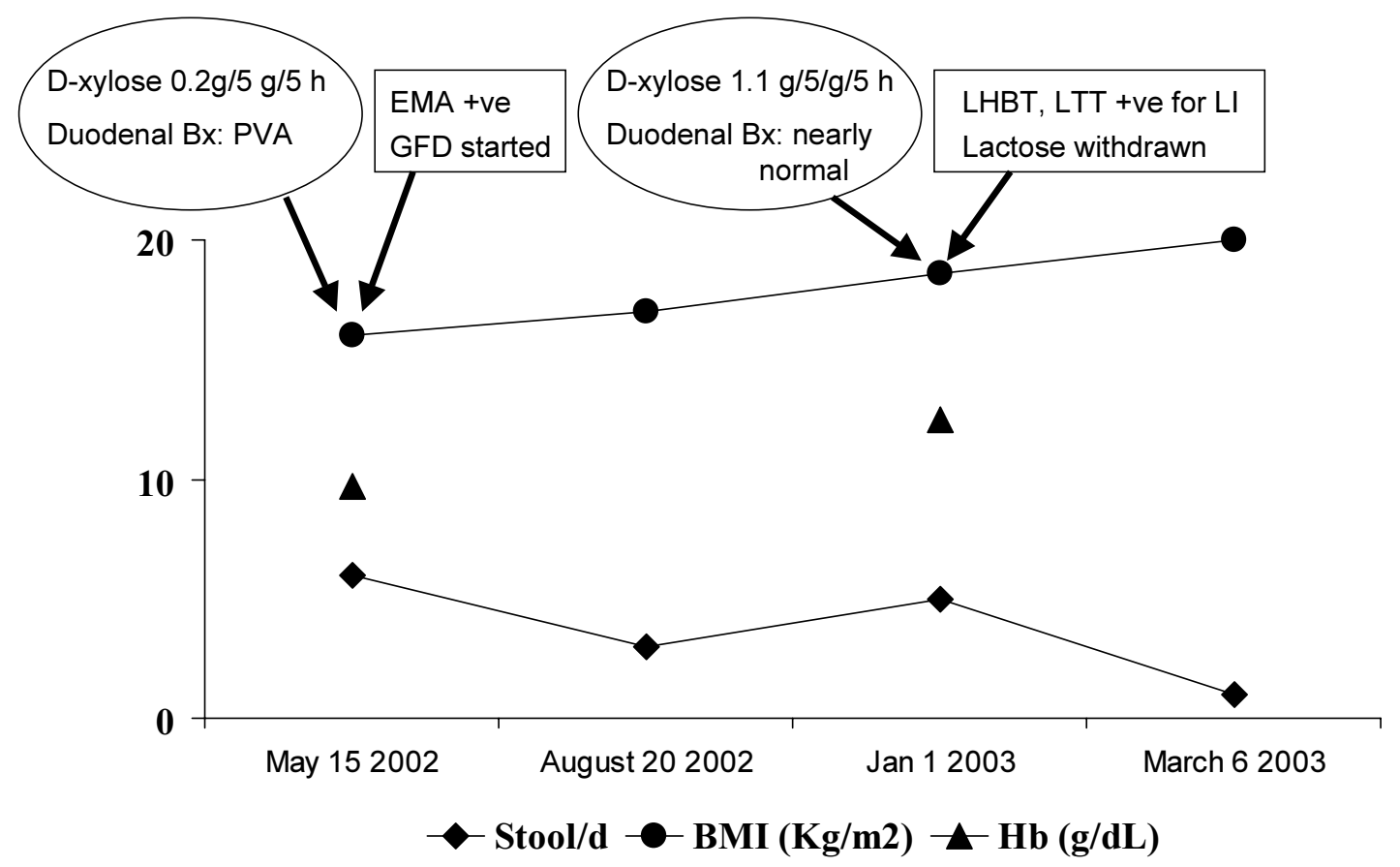

\section{Figure 2}

Course of the other patient with celiac disease. Her response to gluten free diet (GFD) was inadequate despite a good compliance as she continued to pass 4-5 liquid stools/day. She was found to have lactose intolerance (LI). Inadequate response to GFD might have been due to $\mathrm{LI}$ as withdrawal of lactose from diet resulted in complete resolution of symptoms. Other abbreviations used: Bx: biopsy; PVA: partial villous atrophy; EMA: anti-endomysial antibody; LHBT: lactose hydrogen breath test; LT: lactose tolerance test.

enzymes including lactase [9]; primary lactase deficiency is somewhat uncommon too [10]. However, a definite diagnosis of lactose intolerance is important as a firm diagnosis helps the clinician as well as the patient to completely withdraw lactose containing foods, compliance to which may not be so easy for a patient with celiac disease already on significant dietary restriction without a definite diagnosis, particularly if the patient is vegetarian. The second patient continued to have diarrhea despite improvement in D-xylose test and duodenal biopsy, which led us to suspect a predominantly osmotic factor as the cause of diarrhea. Therefore, we investigated for lactose intoler- ance contributing to osmotic diarrhea. Normal result of D-xylose test was helpful as it suggested normalization of intestinal mucosa; D-xylose test has a high sensitivity to detect abnormal mucosa causing MAS [11]. In fact, serial tests of intestinal permeability, which are based on a principle similar to D-xylose test, have been used successfully to non-invasively predict normalization of intestinal mucosa before undertaking invasive tests like endoscopic duodenal biopsy [12].

Small intestinal bacterial overgrowth in patients with celiac disease may lead to persistent diarrhea due to 
disturbances in luminal digestion and alteration of mucosal function, albeit minor [13]. Bacteria in small intestine in patients with SIBO causes deconjugation of bile acids, which causes watery diarrhea due to stimulation of colonic secretion and steatorrhea due to depletion of bile acid pool [13]. Lactose intolerance results in persistence of diarrhea mainly due to osmotic effect of unabsorbed lactose and flatulence due to production of gas from fermentation of unabsorbed lactose.

Refractory celiac sprue is defined as an initial (primary) or subsequent (secondary) failure of a strict GFD to restore normal intestinal structure and function and may result from several mechanisms [14]. It is important to keep all these causes of refractory celiac sprue in mind and to investigate and treat for all these factors [14]. Though SIBO and secondary lactose intolerance are expected and known to be common in celiac disease, until recently $[3,15]$, only a few reports have been published on this issue $[16,17]$. Though normalization of duodenal histology may take long time up to one to two years, clinical response such as reduction in diarrhea and weight gain occurs within weeks [14]. Failure of normalization of duodenal histology has been proposed as a criterion for diagnosis of refractory sprue [14]. Persistent symptoms despite normalization of duodenal histology may suggest causes other than refractory sprue such as SIBO and lactose intolerance.

In conclusion, we believe that if diarrhea persists in a patient with celiac disease despite improvement in duodenal biopsy and $\mathrm{D}$-xylose absorption, lactose intolerance and SIBO should be suspected; appropriate investigations and treatment for these may result in complete recovery.

\section{List of abbreviations \\ GFD: gluten free diet}

SIBO: small intestinal bacterial overgrowth

MAS: malabsorption syndrome

Hb: hemoglobin

ELISA: enzyme linked immunosorbant assay

CFU: colony forming units

GHBT: glucose 'hydrogen breath test

PPM: parts per million

OCTT: orocecal transit time

BMI: body mass index
HPF: high power field

UK: United Kingdom

LI: lactose intolerance

Bx: biopsy

PVA: partial villous atrophy

EMA: endomysial antibody

LHBT: lactose hydrogen breath test

LT: lactose tolerance test

\section{Declaration of competing interests}

None declared.

\section{Authors' contribution}

Uday C Ghoshal was the clinician involved in the management of these patients, conceived the idea and drafted the manuscript. Ujjala Ghoshal standardized and performed microbiological works for the diagnosis of small intestinal bacterial overgrowth syndrome. Asha Misra performed the hydrogen breath tests. Gourdas Choudhuri supervised the works. All the authors read and approved the manuscript.

\section{Acknowledgement}

We thank the patients who are presented in this report for giving us written consent for publishing their data.

\section{References}

I. Mahindra S, Yaccha SK, Srivastava A, Krishnani N, Aggarwal R, Ghoshal UC, Prasad KK, Naik SR: Celiac disease in Asian Indian children: Anthropometric and histological study. J Pop Health Nutr 200I, 19:204-8.

2. Poddar U, Thapa BR, Nain CK, Prasad A, Singh K: Celiac disease in India: Are they true cases of celiac disease? J Pediatr Gastroenterol Nutr 2002, 35:508-5I2.

3. Tursi A, Brandimarte G, Giorgetti GM: High prevalence of small intestinal bacterial overgrowth in celiac patients with persistence of gastrointestinal symptoms after gluten withdrawal. Am J Gastroenterol 2003, 98:839-43.

4. Marsh MN: Gluten, major histocompatibility complex and small intestine: A molecular and immunological approach to the spectrum of gluten sensitivity (celiac sprue). Gastroenterology 1992, 102:330-54.

5. Ghoshal UC, Ghoshal U, Ayyagari A, Ranjan P, Krishnani N, Misra A, Aggarwal $R$, Naik S, Naik SR: Tropical sprue is associated with contamination of small bowel with aerobic bacteria and reversible prolongation of orocecal transit time. J Gastroenterol Hepatol 2003, 18:540-7.

6. Ghoshal U, Ghoshal UC, Ranjan P, Ayyagari A: Spectrum and antibiotic sensitivity of bacteria contaminating upper gut in patients with malabsorption syndrome in the tropics. $B M C$ Gastroenterology 2003, 3:9 [http://www.biomedcentral.com/l47I230X/3/9].

7. Chiarioni G, Bassotti G, Germani U, Battaglia E, Brentegani MT, Morelli A, et al.: Gluten-free diet normalizes mouth-to-cecum transit of a caloric meal in adult patients with celiac disease. Dig Dis Sci 1997, 42:2100-5. 
8. Lim ML: A perspective on tropical sprue. Curr Gastroenterol Rep 200I, 3:322-7.

9. Farrell RJ, Kelly CP: Celiac sprue and refractory sprue. In: Gastrointestinal and Liver Disease. Pathophysiology, Diagnosis, Management Edited by: Feldman M, Friedman LS, Sleisenger MH. Philadelphia: WB Saunders; 2002:1817-4I.

10. Heitlinger LA, Lebenthal E: Disorders of carbohydrate digestion and absorption. Pediatr Clin North Am 1988, 35:239-55.

II. Bala L, Gowda GAN, Ghoshal UC, Misra A, Bhandari M, Khetrapal $\mathrm{CL}$ : ' $\mathbf{H}$ spectroscopic method for diagnosis of malabsoprtion syndrome: A pilot study. NMR Biomedicine 2004, 17:69-75.

12. Johnston SD, Smye M, Watson RGP: Intestinal permeability test in celiac disease. Clin Lab 200I, 47:143-50.

13. Isaacs PET, Kim YS: The contaminated small bowel syndrome. Am J Med 1979, 67:1049-56.

14. Ryan BM, Kelleher D: Refractory celiac disease. Gastroenterology 2000, I I9:243-5I.

15. Abdulkarim AS, Burgart LJ, See J, Murray JA: Etiology of nonresponsive celiac disease: Reults of a systemic approach. $\mathrm{Am} J$ Gastroenterol 2002, 97:2016-2I.

16. Fine K, Meyer R, Lee E: The prevalence and cause of chronic diarrhea in patients with celiac sprue treated with a gluten free diet. Gastroenterology 1997, I I 2: 1830-8.

17. Roufail W, Ruffin J: Effect of antibiotic therapy on gluten sensitive enteropathy. Am J Dig Dis 1966, I I:587-93.

\section{Pre-publication history}

The pre-publication history for this paper can be accessed here:

http://www.biomedcentral.com/1471-230X/4/10/pre

pub

Publish with Biomed Central and every scientist can read your work free of charge

"BioMed Central will be the most significant development for disseminating the results of biomedical research in our lifetime. "

Sir Paul Nurse, Cancer Research UK

Your research papers will be:

- available free of charge to the entire biomedical community

- peer reviewed and published immediately upon acceptance

- cited in PubMed and archived on PubMed Central

- yours - you keep the copyright 